\title{
VEGF INCORPORATED INTO CALCIUM PHOSPHATE CERAMICS PROMOTES VASCULARISATION AND BONE FORMATION IN VIVO
}

\author{
E. Wernike ${ }^{1}$, M.-O. Montjovent ${ }^{1,2}$, Y. Liu ${ }^{3,4}$, D. Wismeijer ${ }^{3}$, E.B. Hunziker ${ }^{4}$, K.-A. Siebenrock ${ }^{2}$, W. Hofstetter ${ }^{1}$, and \\ F.M. Klenke ${ }^{1,2 *}$
}

\begin{abstract}
${ }^{1}$ Group for Bone Biology and Orthopedic Research, Department of Clinical Research, University of Bern, CH-3010 Bern, Switzerland

${ }^{2}$ Department of Orthopedic Surgery, Inselspital, Bern University Hospital, CH-3010 Bern, Switzerland

${ }^{3}$ Department of Oral Implantology and Prosthdontics, Academic Center for Dentistry Amsterdam (ACTA), NL-1066

EA Amsterdam, The Netherlands

${ }^{4}$ Center of Regenerative Medicine for Skeletal Tissues, Department of Clinical Research, University of Bern, CH3010 Bern, Switzerland
\end{abstract}

\begin{abstract}
Bone formation and osseointegration of biomaterials are dependent on angiogenesis and vascularization. Angiogenic growth factors such as vascular endothelial growth factor (VEGF) were shown to promote biomaterial vascularization and enhance bone formation. However, high local concentrations of VEGF induce the formation of malformed, nonfunctional vessels. We hypothesized that a continuous delivery of low concentrations of VEGF from calcium phosphate ceramics may increase the efficacy of VEGF administration. VEGF was co-precipitated onto biphasic calcium phosphate $(\mathrm{BCP})$ ceramics to achieve a sustained release of the growth factor. The co-precipitation efficacy and the release kinetics of the protein were investigated in vitro. For in vivo investigations BCP ceramics were implanted into critical size cranial defects in Balb/c mice. Angiogenesis and microvascularization were investigated over 28 days by means of intravital microscopy. The formation of new bone was determined histomorphometrically. Co-precipitation reduced the burst release of VEGF. Furthermore, a sustained, cell-mediated release of low concentrations of VEGF from BCP ceramics was mediated by resorbing osteoclasts. In vivo, sustained delivery of VEGF achieved by protein co-precipitation promoted biomaterial vascularization, osseointegration, and bone formation. Short-term release of VEGF following superficial adsorption resulted in a temporally restricted promotion of angiogenesis and did not enhance bone formation. The release kinetics of VEGF appears to be an important factor in the promotion of biomaterial vascularization and bone formation. Sustained release of VEGF increased the efficacy of VEGF delivery demonstrating that a prolonged bioavailability of low concentrations of VEGF is beneficial for bone regeneration.
\end{abstract}

Keywords: Biomaterials, calcium phosphates, drug delivery, tissue engineering, angiogenesis, bone formation.

*Address for correspondence:

Frank M. Klenke

Department of Orthopedic Surgery

Inselspital, Bern University Hospital

CH-3010 Bern, Switzerland

Telephone Number: +41-31-632 2111

FAX Number: +41-31-632 3600

E-mail: frank.klenke@bluewin.ch

\section{Introduction}

Loss of bone caused by trauma, resection of tumors, and total arthroplasty revision surgery represents a major problem in orthopedic surgery and traumatology. Autologous bone is widely accepted as the standard material to reconstruct skeletal defects providing essential elements such as osteogenic cells, osteoinductive factors, and an osteoconductive matrix for bone formation. However, there are critical limitations associated with the graft harvest, such as donor site morbidity, prolonged surgery time and limited supply (Finkemeier, 2002).

Calcium phosphate $(\mathrm{CaP})$ based ceramics represent a promising group of biomaterials for clinical use as bone substitute materials. These materials are known for their osteoconductive properties. However, bone formation observed after implantation of CaP ceramics is often insufficient thus limiting the long-term mechanical stability of bone defect reconstructions with these materials. Most research to improve the biological properties of $\mathrm{CaP}$ ceramics has focused on the local delivery of osteoinductive growth factors such as bone morphogenetic proteins (BMPs). More recently, angiogenic growth factors such as vascular endothelial growth factor (VEGF) have gained increasing attention due to the pivotal contribution of angiogenesis during bone healing (Peng et al., 2002; Peng et al., 2005; Street et al., 2002). The establishment of a dense vascular network is essential to provide the site of biomaterial implantation with oxygen, nutrients, soluble factors, and cells and to ensure the evacuation of metabolites. VEGF was shown to promote vascularization of polymeric and calcium phosphate based bone substitute materials (Geiger et al., 2007; Huang et al., 2005; Kaigler et al., 2006). Furthermore, several studies provided evidence that local delivery of VEGF from carrier biomaterials improved the healing of critical size bone defects (Clarke et al., 2007; Geiger et al., 2005; Kaigler et al., 2006).

The narrow therapeutic range of VEGF complicates the efficient local delivery of the growth factor. High VEGF concentrations were shown to increase vascular permeability, cause vessel leakage and induce the formation of malformed, non-functional blood vessels (Chang et al., 2000; Drake and Little, 1995; Horowitz et al., 1997; Vajanto et al., 2002). The majority of VEGF delivery systems described previously lead to the release of high amounts of the growth factor during the initial 
phase after biomaterial implantation (Ennett et al., 2006; Gao et al., 2007; Kempen et al., 2009; Murphy et al., 2004; Patel et al., 2008). Short-term release of VEGF was shown to promote angiogenesis previously (Ennett et al., 2006; Kempen et al., 2009; Murphy et al., 2004). However, a sustained release of the growth factor may increase the growth factor's efficacy for bone regeneration due to its stimulatory effects on both angiogenesis and osteoblast differentiation (Gerber et al., 1999; Mayr-Wohlfart et al., 2002; Street et al., 2002). We have previously implemented a delivery system achieving a long-term release of proteins from biphasic calcium phosphate (BCP) ceramics in vitro by incorporating the proteins into a layer of calcium phosphate (Liu et al., 2001; Wernike et al., 2010). We now aimed to investigate the effects of a sustained release of VEGF from calcium phosphate ceramics on biomaterial vascularization and bone formation in vivo.

\section{Materials and Methods}

Bone substitute materials. Custom made porous BCP ceramics (pore size $150-200 \mu \mathrm{m}$, porosity $75 \% \pm 5 \%$ ) composed of $80 \%$ hydroxyapatite (HA) and $20 \% \beta$ tricalcium phosphate $(\beta$-TCP) were provided by Progentix BV (MB Bilthoven, The Netherlands). Ceramic cylinders were prepared with a diameter of $14 \mathrm{~mm}$ for in vitro experiments and $4 \mathrm{~mm}$ for in vivo experiments; discs with a thickness of $0.5 \mathrm{~mm}$ were cut using a diamond saw. The BCP discs were cleaned with ethanol and UV sterilized (4 hours) prior to use.

Coating of BCP ceramics with rhVEGF and [ $\left.{ }^{125} I\right]-$ VEGF. Recombinant human vascular endothelial growth factor (rhVEGF) was kindly provided by Genentech Inc. (South San Francisco, CA, USA). ${ }^{125}$ I labeled VEGF ([ $\left.{ }^{125} \mathrm{I}\right]-$ VEGF) was purchased from Perkin Elmer (Waltham, MA, USA). BCP ceramics were coated with protein either by superficial adsorption or by protein co-precipitation. rhVEGF or $\left[{ }^{125} \mathrm{I}\right]$-VEGF was superficially adsorbed to the surface of the materials by immersion of BCP discs in an aqueous protein solution (total volume of $2.5 \mathrm{ml}$ ) for 48 hours at $37^{\circ} \mathrm{C}$ in 24 -well plates using a custom made holder. The co-precipitation was performed as described previously (Wernike et al., 2010). The co-precipitation of proteins and calcium phosphate onto BCP ceramics comprised a two-layer coating. Ceramic materials were first immersed for 24 hours at $37^{\circ} \mathrm{C}$ in 5-times concentrated simulated body fluid $\left(\mathrm{Na}^{+} 733.5 \mathrm{mM}, \mathrm{Cl}^{-} 720.0 \mathrm{mM}, \mathrm{HPO}_{4}{ }^{2-}\right.$ $5.0 \mathrm{mM}, \mathrm{SO}_{4}^{2-} 2.5 \mathrm{mM}$ ) under high-nucleation conditions in the presence of $\mathrm{Mg}^{2+}(7.5 \mathrm{mM})$ to inhibit crystal growth. An amorphous layer of calcium phosphate was thereby created which served as a seeding substratum for the subsequent crystalline calcium phosphate layer. The crystalline calcium phosphate layer was generated by incubation of the BCP discs in $2.5 \mathrm{ml}$ of a supersaturated solution of calcium phosphate $\left(\mathrm{Na}^{+} 140.0 \mathrm{mM}, \mathrm{Ca}^{2+}\right.$ $4.0 \mathrm{mM}, \mathrm{Cl}^{-} 144.0 \mathrm{mM}, \mathrm{HPO}_{4}^{2-} 2.0 \mathrm{mM}$ ) for 48 hours at $37^{\circ} \mathrm{C}$ in the presence of rhVEGF or $\left[{ }^{125} \mathrm{I}\right]-\mathrm{VEGF}$. $\left[{ }^{125} \mathrm{I}\right]-\mathrm{VEGF}$ and rhVEGF were thereby incorporated in the crystalline calcium phosphate layer. rhVEGF was used at a concentration of $1 \mu \mathrm{g} / \mathrm{ml}$ for in vitro experiments and 1 and $5 \mu \mathrm{g} / \mathrm{ml}$ for in vivo experiments. For the first 60 minutes of the coatings, a vacuum was applied to remove air trapped within the porous structure of the BCP discs.

\section{In Vitro Experiments}

Cell Cultures. Bone marrow cells (BMC) were harvested from femora and tibiae of approximately 6 -week-old, male $d d y$ mice. After equilibration of the BCP discs in $\alpha$-MEM culture media supplemented with 10\% FBS (not heat inactivated, Gibco, Basel, Switzerland) and 1\% Pen/Strep $(100 \mathrm{U} / \mathrm{ml}$ and $100 \mu \mathrm{g} / \mathrm{ml}$ of Penicillin G and Streptomycin, respectively; Gibco, Basel, Switzerland) for 2 hours, $1 \times 10^{6}$ cells were seeded onto each BCP disc. The cells were cultured in $\alpha$-MEM culture media containing $10 \%$ FBS and $1 \% \mathrm{Pen} / \mathrm{Strep}$ in the presence of $30 \mathrm{ng} / \mathrm{ml}$ colonystimulating factor-1 (CSF-1, Chiron Corporation, Emeryville, CA, USA; differentiation towards the monocyte/macrophage lineage) or in the presence of 30ng/ $\mathrm{ml} \mathrm{CSF}-1$ and $50 \mathrm{ng} / \mathrm{ml}$ receptor activator of nuclear factor kappa-B ligand (RANKL, Peprotech, London, UK; differentiation towards the osteoclast lineage) to induce the cell-mediated release of co-precipitated proteins as described previously (Wernike et al., 2010). The differentiation of BMCs towards the monocyte/ macrophage and osteoclast lineage was confirmed using a Hoechst 33342/tartrate resistant acid phosphatase (TRAP) staining protocol as described previously (data not shown) (Wernike et al., 2010). The culture media were changed in 3 day intervals.

Quantification of [ ${ }^{125}$ I]-VEGF Uptake. The uptake of $\left[{ }^{125} \mathrm{I}\right]-\mathrm{VEGF}$ onto the BCP discs was quantified by gamma counting. $\left[{ }^{125} \mathrm{I}\right]-\mathrm{VEGF}$ coated $\mathrm{BCP}$ discs were dissolved in $2 \mathrm{ml}$ of $1 \mathrm{M}$ hydrochloric acid $(\mathrm{HCl})$. The gamma radiation of the solution was then measured with a gamma counter (Packard, Cobra II, TopLab GmbH, Switzerland).

Experimental protocol of time-course experiments. Investigations of the rhVEGF release from the $\mathrm{BCP}$ discs were performed over a period of 19 days. The release of rhVEGF was quantified by ELISA (Human VEGF ELISA Development, R\&D Systems Europe, UK). Coated BCP discs were equilibrated in $\alpha$-MEM culture media for 24 hours. Afterwards, the discs were incubated in $\alpha$-MEM culture media for another 18 days to investigate the spontaneous release and the biological activity of rhVEGF. To analyze the cell-mediated release and the biological activity of rhVEGF released by cell-mediated material resorption, $1 \times 10^{6}$ murine $\mathrm{BMCs}$ were seeded onto the $\mathrm{BCP}$ discs and cultured for 18 days in the presence of CSF-1 alone or in the presence of CSF-1 and RANKL as described above. The culture medium was changed in 3 day intervals and processed for subsequent analysis.

\section{In Vivo Experiments}

Cranial window preparation. Male 10 week old Balb/c mice (BALB7cAnNCrl; Charles River Sulzfeld, Germany) were used for this study, which was approved by the local committee for animal experimentation (BVET, Berne, Switzerland) and conducted in accordance with its regulations. 
BCP ceramic discs were implanted into a cranial window preparation in Balb/c mice (Klenke et al., 2008). In this animal model, critically sized calvaria defects serve as the site of orthotopic implantation of ceramic materials. The mice were anaesthetized by subcutaneous injection of a mixture of fentanyldihydrogencitrate $(50 \mu \mathrm{g} / \mathrm{kg}$ body weight), medetomidine hydrochloridum $(500 \mu \mathrm{g} / \mathrm{kg}$ body weight), and climazolame $(5 \mathrm{mg} / \mathrm{kg}$ body weight). After shaving and disinfection of the scalp with $70 \%$ ethanol an oval area of the scalp $\left(15 \times 10 \mathrm{~mm}^{2}\right)$ was removed to expose the frontal and parietal bones with the coronal, lambdoid and sagittal sutures. Using a dental drilling device, circular 4mm-diameter full-thickness defects were generated within the calvaria. Care was taken to avoid mechanical or thermal damage to the dura mater and the underlying brain tissue. If this occurred, the animal was euthanized immediately and excluded from the study. If bleeding from the bone occurred, the surgical procedure was interrupted to clear the site by swabbing with a sterile Q-tip. Ceramic discs were then inserted into the defect. To protect the tissue from dehydration and mechanical damage, the exposed site was covered with a circular, $7 \mathrm{~mm}$ diameter glass slip (Assistent, Sondheim, Germany), which was secured to the bone margin with cement (a mixture of ethylcyanoacrylate glue; Pattex ${ }^{\circledR}$; Blitz Kleber, Henkel, Düsseldorf, Germany; and a methylmethacrylate polymer; GC Ostron ${ }^{\circledR}$-powder; GC Europe, Leuven, Belgium). After hardening of the sealant, the anesthesia was antagonized by subcutaneous injection of the following antidote mixture: atipamezoli hydrochloridum $(1.25 \mathrm{mg} / \mathrm{kg})$, sarmazenilum $(0.5 \mathrm{mg} / \mathrm{kg})$ and buprenorphinum $(0.075 \mathrm{mg} /$ $\mathrm{kg})$.

Intravital microscopy. Intravital fluorescence videomicroscopy was performed 7, 14, and 28 days after implantation using a vertical illumination fluorescence microscope unit (Olympus Schweiz AG, Volketswil, Switzerland) equipped with $\mathrm{x}-2.5, \mathrm{x}-20$ and $\mathrm{x}-40$ objectives and a fluorescence filter for green light (excitation wavelength: 460-480nm, emission wavelength: 495$540 \mathrm{~nm})$. For the off-line analysis, regions of interest were recorded on a digital hard disk system, which was connected to a digital microscope camera. The microcirculation was visualized by intravenous (iv) injection of $50 \mu 1$ of the high molecular weight plasma marker fluorescein-isothiocyanate-labeled (FITC) dextran (FD 2000, Sigma Aldrich; Buchs, Switzerland; 2.5\% concentrated solution in $0.9 \%$ saline, molecular weight $2000 \mathrm{kD}$ ). Intravenous injection of $50 \mu \mathrm{l}$ low molecular weight FITC dextran (FD150S Sigma Aldrich; Buchs, Switzerland, 5\% concentrated solution in $0.9 \%$ saline, molecular weight $150 \mathrm{kD}$ ) was used to determine vessel leakage. Vessels were recorded directly before and 1 minute post injection at x-40 maginification. Mice were kept under anesthesia (see above) during microscopy. To terminate anesthesia an antidote mixture containing atipamezole hydrochloridum $(1.25 \mathrm{mg} / \mathrm{kg}$ body weight), sarmazenilum $(0.5 \mathrm{mg} / \mathrm{kg}$ body weight $)$ and naloxone hydrochloridum $(0.6 \mathrm{mg} / \mathrm{kg}$ body weight) was injected subcutaneously.

After 28 days the in vivo experiments were terminated and the animals were euthanized with $\mathrm{CO}_{2}$. The implanted material was immediately extracted together with the surrounding calvarial and brain tissues for histomorphometric analysis. Each specimen was chemically fixed in $4 \%$ buffered paraformaldehyde solution, dehydrated in a series of ethanol, and embedded in methylmethacrylate.

Off-line analysis of angiogenesis and vessel leakage. The functional capillary density (FCD) within the implantation site was defined as the total length of the erythrocyteperfused capillaries (in $\mathrm{mm}$ ) per area (in $\mathrm{mm}^{2}$ ). This parameter was previously described to assess microvascular perfusion in various tissues (Hoffmann et al., 2004; Leunig et al., 1992; Nolte et al., 1995; Rucker et al., 2006). FCD analysis was performed on digital fluorescence images using Image J (Research Services Branch, NIH, Bethesda, Maryland; U.S.). The extravasation of low molecular weight FITC dextran into the peri-vascular tissue was used as a measure of vessel leakage. The measurement of vascular leakage has been established as a parameter to determine the maturity of blood vessels (Gerlowski and Jain, 1986; Leunig et al., 1992). Using Adobe Photoshop (Photoshop CS4, Adobe Inc.) the grey values of the peri-vascular tissue were measured before injection of FITC dextran and 1 minute after injection in 4 independent regions of interest (ROI). The percental change of the grey values within the perivascular tissue served as the measure of plasma extravasation of FITC dextran and was calculated as [ (grey value post-injection/grey value pre-injection) x 100].

Quantitative Histomorphometry. The embedded tissue samples were cut perpendicular to the sagittal plane. Ground sections of $300 \mu \mathrm{m}$, separated by a constant distance of $300 \mu \mathrm{m}$, were cut using a saw microtome from Leica (Leica SP1600, Leica Microsystems, Glattbrugg, Switzerland). Each specimen yielded five to six serial sections. The sections were polished and stained using McNeal's tetrachrome (MacNeal, 1922; Penney et al., 2002). The volume of newly-formed bone was quantified on light microscopic images of the sections using Cavalieri's method (Gundersen and Jensen, 1987). The volume of newly formed bone $\left(\mathrm{V}_{\text {bone }}\right)$, the bone-interfacecontact (BIC) area and the volume density of bone $\left(\mathrm{V}_{\text {bone }} /\right.$ volume of ceramic pores) were determined using the cycloid test system described by Baddeley et al. (Baddeley et al., 1986). To verify the results on vessel density obtained with intravital microscopy analysis, the vessel density was also quantified morphometrically. For this purpose, the number of vessel cross-sections per volume unit $\left(N_{\mathrm{ves}} / \mathrm{mm}^{3}\right)$ was determined based on Cavalieri's method (Gundersen and Jensen, 1987).

Statistics. All numerical data are presented as mean values together with the standard deviation. The data were statistically evaluated by ANOVA using SPSS ${ }^{\circledR}$ software for Mac (Version 16, SPSS Inc., Chicago, IL, USA). Pairwise multiple comparisons were made using the Tukey test. Differences were considered to be statistically significant if the $p$-value was less than 0.05 . 


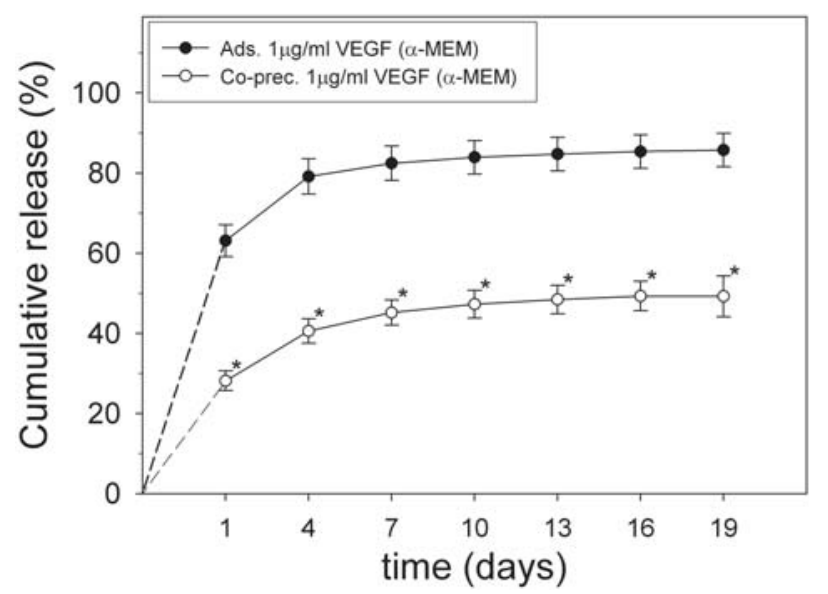

Fig. 1. The passive release of rhVEGF was determined over the course of 19 days with ELISA. rhVEGF was loaded onto BCP discs at a concentration of $1 \mu \mathrm{g} / \mathrm{ml}$. rhVEGF was adsorbed (Adsorption) and coprecipitated (Co-prec.) onto the ceramic materials using coating volumes of $2.5 \mathrm{ml}$. Mean values are represented \pm standard deviation ( $\mathrm{n}=6$ for each group), $* p<0.001$ vs. Adsorption.

\section{Results}

\section{In Vitro Evaluation}

Coating efficacy. The uptake of $\left[{ }^{125} \mathrm{I}\right] \mathrm{VEGF}$ by BCP ceramics was quantified after dissolution of the ceramics in $2 \mathrm{ml} 1 \mathrm{M}$ hydrochloric acid. The coating efficacy was calculated as the percentage of the protein immobilized onto the ceramics in relation to the amount of protein within the coating solution. The absolute uptake of $\left[{ }^{125} \mathrm{I}\right] \mathrm{VEGF}$ in relation to the dry weight of the ceramics ( $\mathrm{ng} / \mathrm{mg}$ ) was determined. Two independent uptake experiments with six samples for each experimental condition were conducted. The coating efficacy and the absolute uptake were higher with the co-precipitation technique as compared to superficial adsorption of the growth factor [Coating efficacy: Adsorption $1 \mu \mathrm{g} / \mathrm{ml}: 39.7 \pm 0.3 \%$, Co-precipitation $1 \mu \mathrm{g} / \mathrm{ml}: 46.4 \pm 1.1, p<0.001)$; absolute uptake: Adsorption $11.79 \pm 0.64 \mathrm{ng} / \mathrm{mg}$ ceramic (ceramic weight $84.4 \pm 4.3 \mathrm{mg}$ ), Co-precipitation: $13.92 \pm 0.42 \mathrm{ng} / \mathrm{mg}$ ceramic (ceramic weight $83.4 \pm 3.0 \mathrm{mg}), p=0.009]$.

\section{Passive and cell-mediated release of rhVEGF from BCP} ceramics. The passive and the cell-mediated release of rhVEGF were monitored over 19 days (Fig. 1). Coprecipitation of rhVEGF improved the retention of the protein on the ceramic materials markedly. Within 19 days, $49.6 \pm 3.7 \%$ of rhVEGF co-precipitated to BCP ceramics were released passively. In contrast, adsorption of rhVEGF to $\mathrm{BCP}$ ceramics resulted in a passive release of $85.8 \pm$ $4.2 \%$ of the protein loaded onto the materials. The decrease of the passive release achieved with the co-precipitation technique was mainly attributed to a decrease of the burst release of rhVEGF within the first 24 hours. While adsorption of rhVEGF resulted in a burst release of $63.1 \pm$ $4.0 \%$, the burst release found after co-precipitation was reduced to $28.2 \pm 2.5 \%$.
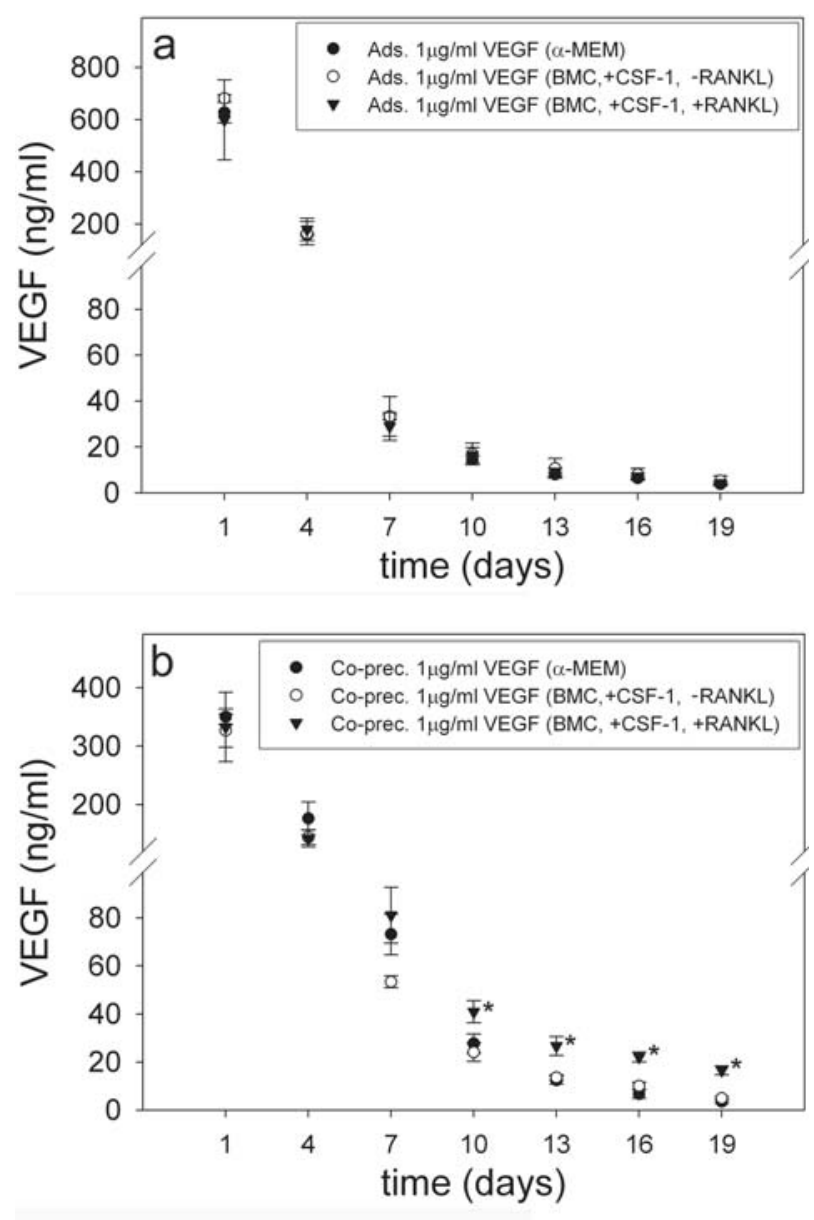

Fig. 2. The passive release after incubation of ceramics in $\alpha$-MEM culture media and the cell-mediated release in the presence of murine bone marrow cells were investigated over 19 days. Graphs show the release of rhVEGF loaded to the ceramics at a concentration of $1 \mu \mathrm{g} / \mathrm{ml}$. Adsorption (a): Release of rhVEGF adsorbed to the surface of the ceramics with a volume of $2.5 \mathrm{ml}$. Co-precipitation (b): Release of rhVEGF co-precipitated to the ceramics with $2.5 \mathrm{ml}$ calcium phosphate solution. Mean values are represented $\pm \mathrm{SD}(\mathrm{n}=6$ for each group), *pd"0.05 vs. $1 \mu \mathrm{g} / \mathrm{ml}$ rhVEGF ( $\alpha-\mathrm{MEM})$ and vs. $1 \mu \mathrm{g} / \mathrm{ml}$ rhVEGF (BMC, +CSF-1, -RANKL).

To assess the cell-mediated release of rhVEGF, BMCs were grown on the ceramics and differentiated to monocytes/macrophages and osteoclasts, respectively. The presence of BMCs on ceramics to which rhVEGF was adsorbed did not influence the release kinetics of the growth factor (Fig. 2A). In BCP ceramics co-precipitated with rhVEGF, BMCs cultured in the presence of CSF-1 and RANKL were able to promote the release of rhVEGF (Fig. 2B). From day 10, BMCs differentiated to osteoclasts gave rise to a cell-mediated release of rhVEGF. BMCs differentiated towards monocytes/macrophages did not influence the release kinetics of co-precipitated rhVEGF.

\section{In Vivo Evaluation}

Vascularization of biomaterials and bone formation. Biphasic calcium phosphate ceramic discs were implanted into critical size defects in mice. Vessel formation was 
Table 1: Vascular leakage

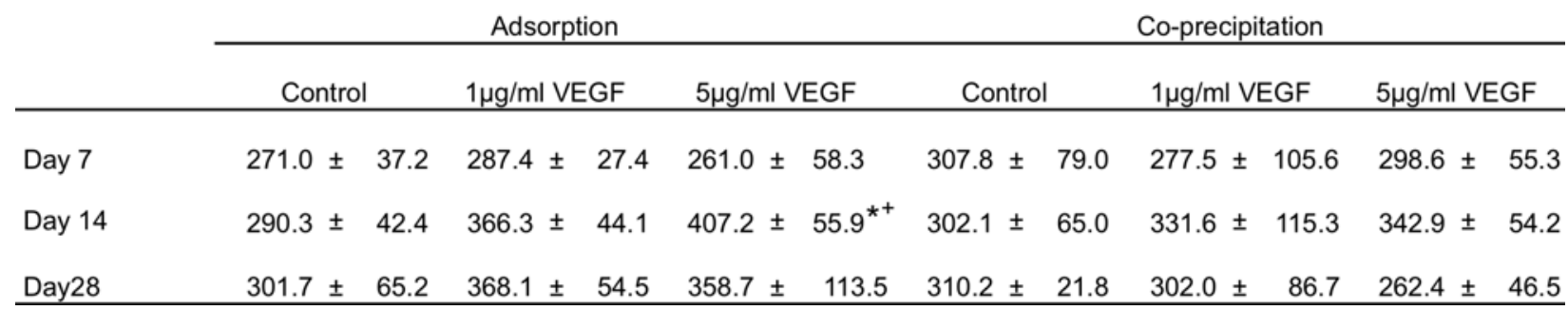

To determine the vascular leakage the grey values of the peri-vascular tissue were measured before injection of FITC dextran and 1 minute after injection. The change of the grey values within the peri-vascular tissue served as the measure of plasma extravasation of FITC dextran and was calculated as [(grey value post-injection/grey value preinjection) $\mathrm{x}$ 100]. The values of vascular leakage during 28 days after implantation of BCP ceramics into the cranial window preparation are shown. BCP ceramics were loaded with rhVEGF at concentrations of $1 \mu \mathrm{g} / \mathrm{ml}$ and $5 \mu \mathrm{g} / \mathrm{ml}$ by means of superficial adsorption and protein co-precipitation. Mean values are represented \pm standard deviation, ${ }^{*} p<0.05$ vs. Control at the same point in time, ${ }^{+} p<0.05$ vs. day 7 of the same group.

investigated by means of intravital microscopy on days 7 , 14 and 28 and was evaluated qualitatively and quantitatively.

Analysis of vessel formation. All experimental groups showed similar functional capillary densities 7 days postoperatively. As shown in Figure 3, FCD increased significantly between day 7 and 14 in all experimental conditions. At day 14, ceramics adsorbed with rhVEGF at a concentration of $5 \mu \mathrm{g} / \mathrm{m}$ and ceramics co-precipitated with rhVEGF at a concentration of $1 \mu \mathrm{g} / \mathrm{ml}$ and $5 \mu \mathrm{g} / \mathrm{ml}$ showed significantly higher FCDs as compared to the respective controls. rhVEGF adsorbed to BCP ceramics induced the formation of irregularly shaped, tortuous blood vessels (Fig. 4A). In contrast, the incorporation of rhVEGF into $\mathrm{BCP}$ ceramics resulted in the formation of less tortuous blood vessels with reduced branching (Fig. 4C). A significant increase of the FCD between day 14 and 28 was observed exclusively in ceramics co-precipitated with rhVEGF at a concentration of $5 \mu \mathrm{g} / \mathrm{ml}$. Co-precipitation of rhVEGF at a concentration of $1 \mu \mathrm{g} / \mathrm{ml}$ and adsorption of rhVEGF at concentrations of $1 \mu \mathrm{g} / \mathrm{ml}$ and $5 \mu \mathrm{g} / \mathrm{ml}$ resulted in unchanged FCDs between day 14 and 28 postoperatively. The increase of FCD in ceramics to which rhVEGF was co-precipitated at a concentration of $5 \mu \mathrm{g} / \mathrm{ml}$ was not associated with a change in the morphology of the blood vessels. Between day 14 and 28, the vascular networks maintained their regularly organized conformation (Fig. 4C, D). At 28 days, ceramics coprecipitated with rhVEGF showed increased FCDs in comparison to their controls whereas adsorption of rhVEGF did not enhance FCD independent of the employed rhVEGF concentration.

Vascular leakage. To evaluate the functional integrity and the maturation of newly formed blood vessels, the vascular leakage was determined. The percent change of the grey values is shown in Table 1. Vascular leakage showed a significant increase between days 7 and 14 after implantation of BCP ceramics adsorbed with rhVEGF at a concentration of $5 \mu \mathrm{g} / \mathrm{ml}$. The value of the vascular leakage

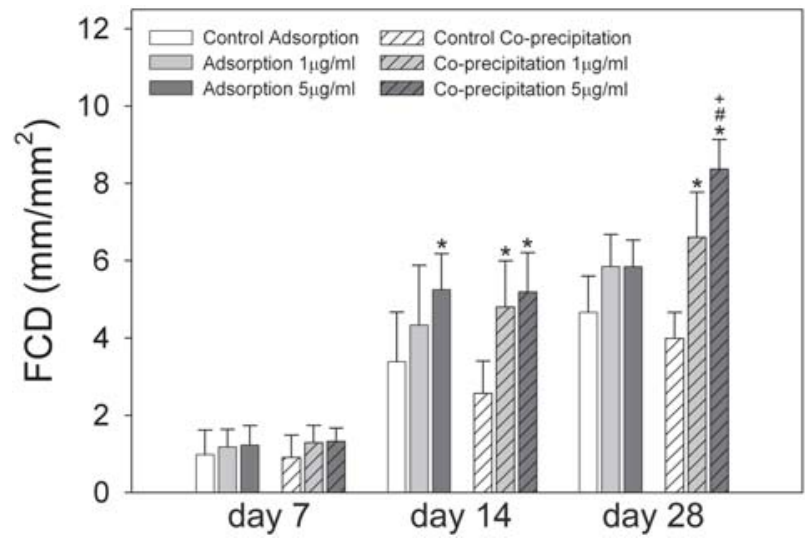

Fig. 3. Vascularization of BCP ceramics was analyzed over 28 days by intravital microscopy. The graph depicts the functional capillary densities (FCD) on days 7,14 , and 28 after implantation. Mean values \pm standard deviation; $* p<0.05$ vs. control (same time point); ${ }^{\#} p<0.05$ vs. co-precipitation of $1 \mu \mathrm{g} / \mathrm{ml} \mathrm{rhVEGF}$ and adsorption of 1 and $5 \mu \mathrm{g} / \mathrm{ml} \mathrm{rhVEGF}$ (same time point); ${ }^{+} p<0.05$ vs. adsorption and co-precipitation of 1 and $5 \mu \mathrm{g} / \mathrm{ml} \mathrm{rhVEGF}$ on day 14 .

at day 14 in this experimental group was significantly higher as compared to the values of the respective controls at the same time point. In all the other experimental groups treated with rhVEGF coated ceramics there was also a tendency towards increased values of vascular leakage 14 days after implantation of ceramic biomaterials found. However, the differences did not reach the level of statistical significance.

\section{Quantitative Histomorphometry}

Quantitative analysis of bone formation. The formation of new bone on the external surfaces and within the porous structure of the materials was quantified histomorphometrically as shown in Figure 5. Bone formation on the external surface of the materials did not differ among the experimental groups and between the experimental and control groups. As shown in Table 2, 
Table 2: Quantitiative histomorphmetry of bone and vessel formation

\begin{tabular}{|c|c|c|c|c|c|c|}
\hline & \multicolumn{3}{|c|}{ Adsorption } & \multicolumn{3}{|c|}{ Co-precipitation } \\
\hline & Control & $1 \mu \mathrm{g} / \mathrm{ml}$ VEGF & $5 \mu \mathrm{g} / \mathrm{ml}$ VEGF & Control & $1 \mu \mathrm{g} / \mathrm{ml}$ VEGF & $5 \mu \mathrm{g} / \mathrm{ml}$ VEGF \\
\hline V Bone pores $\left(\mathrm{mm}^{3}\right)$ & $0.10 \pm 0.02$ & $0.08 \pm 0.03$ & $0.09 \pm 0.02$ & $0.05 \pm 0.02$ & $0.07 \pm 0.01$ & $0.13 \pm 0.04^{\star \# \ddagger}$ \\
\hline V Bone external $\left(\mathrm{mm}^{3}\right)$ & $0.06 \pm 0.02$ & $0.06 \pm 0.03$ & $0.07 \pm 0.02$ & $0.06 \pm 0.02$ & $0.06 \pm 0.03$ & $0.07 \pm 0.04$ \\
\hline$V_{V}$ Bone pores & $0.19 \pm 0.07$ & $0.12 \pm 0.04$ & $0.17 \pm 0.09$ & $0.16 \pm 0.05$ & $0.13 \pm 0.02$ & $0.23 \pm 0.07^{\text {*\# }}$ \\
\hline$V_{V}$ Bone external & $0.24 \pm 0.08$ & $0.24 \pm 0.07$ & $0.21 \pm 0.1$ & $0.26 \pm 0.09$ & $0.24 \pm 0.11$ & $0.25 \pm 0.12$ \\
\hline BIC pores $(\%)$ & $19.7 \pm 6.2$ & $21.4 \pm 7.1$ & $22.1 \pm 6.6$ & $12.8 \pm 5.2$ & $21.3 \pm 8.0$ & $36.4 \pm 9.6^{\star \#+\ddagger}$ \\
\hline BIC external (\%) & $17.4 \pm 8.5$ & $16.3 \pm 8.3$ & $14.2 \pm 5.5$ & $23.0 \pm 10.6$ & $19.5 \pm 6.7$ & $27.7 \pm 8.7$ \\
\hline$\rho$ Vessel (counts $/ \mathrm{mm}^{3}$ ) & $52.8 \pm 14.9$ & $50.4 \pm 10.7$ & $53.3 \pm 11.3$ & $53.8 \pm 10.9$ & $68.6 \pm 8.4$ & $83.8 \pm 16.5^{\text {\#++ }}$ \\
\hline
\end{tabular}

Bone volumes, bone volume densities, bone interface contact, and vessel cross-sections were determined with quantitative histomorphometry using Cavalieri's method. V bone pores: volume of bone deposited within the macropores; $V$ Bone external: volume of bone formed outside of the ceramics; $V$ bone pores: volume density ratio of bone deposited within the macropores [bone volume in macropores/volume of macropores]; $V_{v}$ bone external: volume density ratio of bone formed outside of the ceramics [new bone volume/defect volume-ceramic volume]; BIC pores: bone-interface contact ratio for the macropore surface, expressed as a percentage; BIC external: bone-interface contact ratio for the external surface of the ceramics, expressed as a percentage; $\rho$ Vessel: number of vessel cross-sections per volume unit. Mean values \pm standard deviation are represented $\left(\mathrm{n}=6\right.$ for each group). ${ }^{*} p<0.05$ vs. Control, ${ }^{*} p<0.05$ vs. Adsorption $1 \mu \mathrm{g} / \mathrm{ml} \mathrm{rhVEGF},{ }^{+} p<0.05 v s$. Adsorption $5 \mu \mathrm{g} / \mathrm{ml} \mathrm{rhVEGF},{ }^{\star} p<0.05 v s$. Co-precipitation $1 \mu \mathrm{g} / \mathrm{ml} \mathrm{VEGF}$.

rhVEGF co-precipitated to BCP ceramics at a concentration of $5 \mu \mathrm{g} / \mathrm{ml}$ enhanced the formation of new bone within the pores of the materials significantly. osseointegration of BCP ceramics was determined with the $\mathrm{BIC}$ ratio. 28 days after implantation of the ceramic materials, BIC was significantly higher in BCP ceramics co-precipitated with $5 \mu \mathrm{g} / \mathrm{ml} \mathrm{rhVEGF}$ as compared to controls and co-precipitation with rhVEGF at a concentration of $1 \mu \mathrm{g} / \mathrm{ml}$. At a concentration of $1 \mu \mathrm{g} / \mathrm{ml}$ the co-precipitation of rhVEGF did not enhance bone formation and osseointegration. Superficial adsorption of rhVEGF did not promote bone formation and osseointegration irrespective of the concentration applied.

Quantitative analysis of vessel formation. To verify the results of biomaterial vascularization obtained from in vivo functional capillary density measurements, vessel formation was quantified histomorphometrically. As shown in table 2, the number of vessel cross-sections per $\mathrm{mm}^{3}$ was similar in ceramics adsorbed with rhVEGF at concentrations of $1 \mu \mathrm{g} / \mathrm{ml}$ and $5 \mu \mathrm{g} / \mathrm{ml}$ and the respective control group. rhVEGF co-precipitated to BCP ceramics at a concentration of $5 \mu \mathrm{g} / \mathrm{ml}$ significantly promoted the formation of new blood vessels within the implantation site. Co-precipitation with rhVEGF at a concentration of $1 \mu \mathrm{g} / \mathrm{ml}$ showed a trend towards enhanced vessel formation but the differences did not reach the level of statistical significance.

\section{Discussion}

Angiogenesis is a prerequisite for bone formation. The newly formed vasculature supplies the site of bone formation with oxygen, nutrients, soluble factors, and cells. (Guenther et al., 1986; Harper and Klagsbrun, 1999). Vascularization also seems to be of particular importance for the healing process following the implantation of bone substitute materials (Kanczler and Oreffo, 2008). The establishment of a dense vascular network is essential for bone formation, osseointegration and the subsequent material replacement by newly formed bone.

Due to the pivotal contribution of angiogenesis during bone healing, the local application of angiogenic growth factors such as VEGF has gained increasing attention. Local delivery of VEGF from growth factor loaded biomaterials was shown to promote angiogenesis and the healing of critical size bone defects (Clarke et al., 2007; Geiger et al., 2005; Kaigler et al., 2006). However, the mode of VEGF delivery seems to influence the efficacy of local VEGF administration critically. The formation of poorly perfused fragile capillaries without connection to the pre-existing circulation as well as the development of angiomas due to immoderate VEGF stimulation has been reported (Chang et al., 2000; Drake and Little, 1995). Diffusive VEGF release from PEG-hydrogels induced malformed capillary growth in chick chorioallantoic assays (CAM). In contrast, prolonged release of hydrogel matrix conjugated VEGF induced the formation of regularly organized vasculature demonstrating the benefits of a sustained exposure of the vasculature to the growth factor (Zisch et al., 2003).

We have previously shown that the incorporation of bovine serum albumin into a layer of calcium phosphate increased the retention of the protein on calcium phosphate ceramics (Liu et al., 2001; Wernike et al., 2010). Consistent with the previous study, the incorporation of rhVEGF into a layer of calcium phosphate reduced the initial burst 

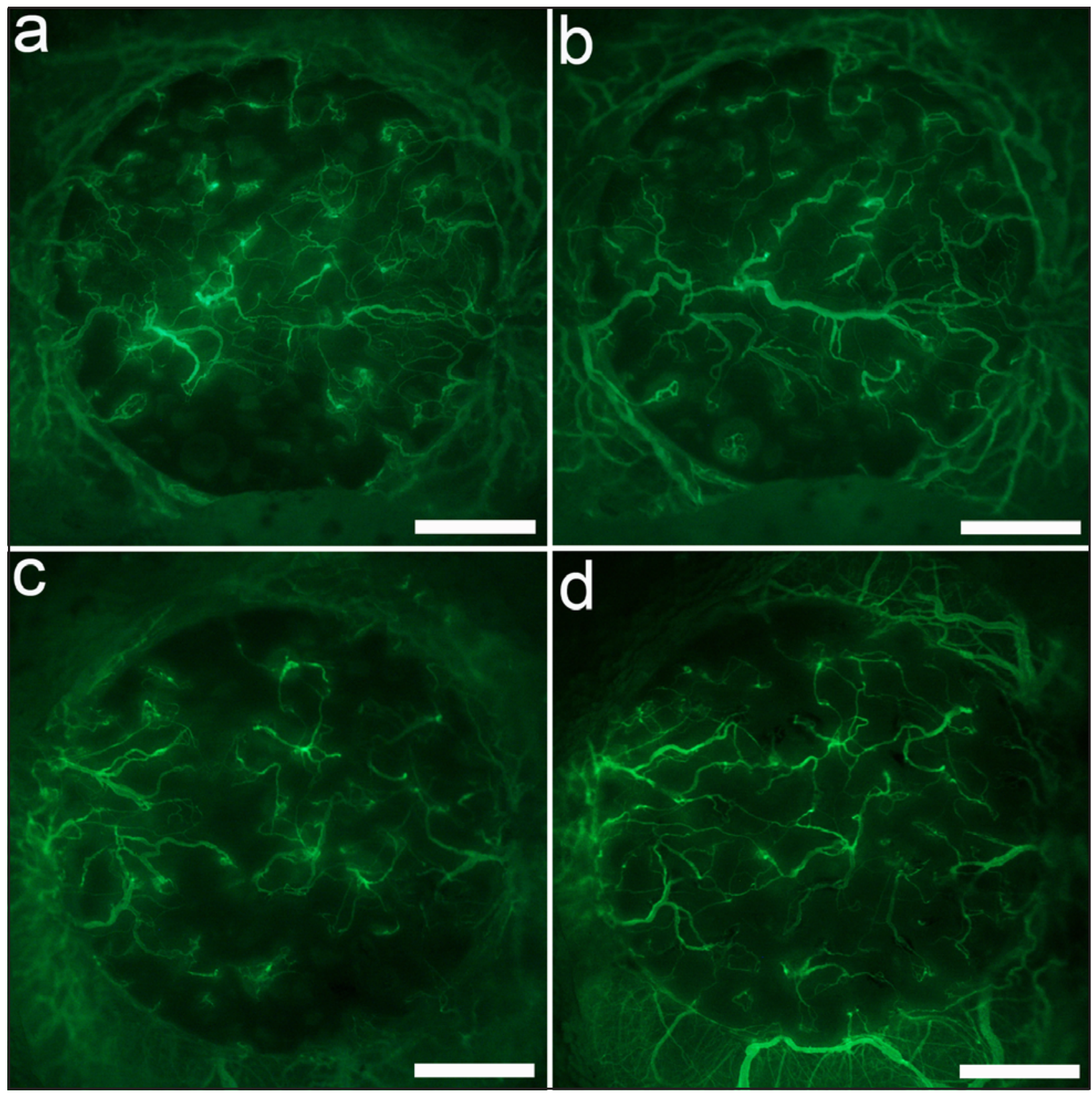

Fig. 4. Vessel formation was visualized with intravital microscopy. Fluorescence images of BCP ceramics implanted into the cranial window preparation were taken after intravenous injection of FITC dextran. BCP ceramics were superficially adsorbed $(\mathrm{a}, \mathrm{b})$ or co-precipitated $(\mathrm{c}, \mathrm{d})$ with rhVEGF at a coating concentration of $5 \mu \mathrm{g} / \mathrm{ml}$. Images show the time course of vessel formation at day 14 (a,c) and at day 28 (b,d), respectively. Scale bars represent $1 \mathrm{~mm}$.

release of the growth factor found with superficial adsorption from $63 \%$ to $28 \%$. Furthermore, a sustained osteoclast-mediated release of low concentrations of rhVEGF was achieved with the co-precipitation technique. In contrast, monocytes/ macrophages did not induce the release of rhVEGF. The release of rhVEGF in the presence of BMCs treated with CSF-1 only was identical to that found after incubation of the ceramics in $\alpha$-MEM culture media indicating that preformed osteoclasts did not contribute to the release of rhVEGF in vitro. The cellmediated release depended on the presence of RANKL initiating the differentiation of BMCs towards the osteoclast lineage on the ceramic materials. These results demonstrate that the incorporation of rhVEGF into calcium phosphate ceramics provides the possibility to retain the protein on the material sufficiently and supply the implantation site with low concentrations of VEGF for a prolonged period of time.

In accordance with previous studies, VEGF promoted biomaterial vascularization in a dose dependent manner in vivo (Ennett et al., 2006; Geiger et al., 2005; Kleinheinz et al., 2005; Murphy et al., 2004; Patel et al., 2008). Furthermore, the promotion of angiogenesis by VEGF depended on the mode of growth factor delivery. The stimulation of angiogenesis by VEGF released from ceramic materials superficially adsorbed with the growth factor was temporarily restricted to the first 2 weeks after biomaterial implantation. Implants adsorbed with $5 \mu \mathrm{g} / \mathrm{ml}$ rhVEGF strongly promoted vessel formation between days 7 and 14 . However, there was no significant promotion of 

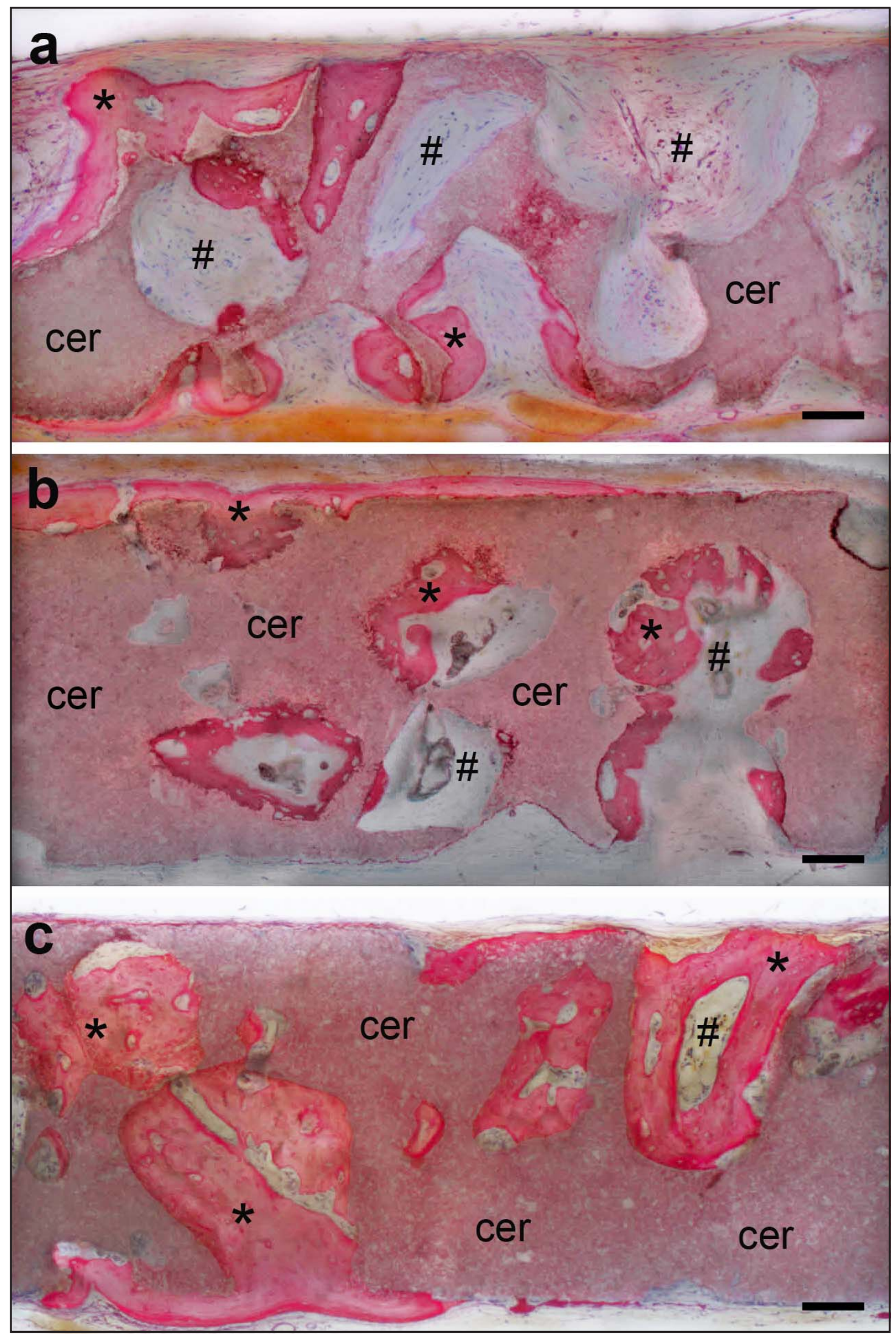

Fig. 5. Light micrographs of $300-\mu \mathrm{m}$-thick vertical sections through cranial defects, 28 days after surgery. The sections were surface-stained with McNeal's tetrachrome. Ceramic (cer); newly-formed bone $(*)$; fibrous tissue (\#). (a) Control ceramic (co-precipitation technique performed with vehicle control solution, no rhVEGF loading). The pores of the materials contained only small deposits of newly-formed bone. Large parts of the porous structure were filled with fibrous tissue. (b) Ceramic adsorbed with rhVEGF at a concentration of $5 \mu \mathrm{g} / \mathrm{ml}$. The extent of new bone formation was similar to that observed in control animals. (c) Ceramic co-precipitated with rhVEGF at a concentration of $5 \mu \mathrm{g} / \mathrm{ml}$. Bone formation within the pores of the materials was more pronounced as compared to the respective control group. Scale bars: $100 \mu \mathrm{m}$. 
angiogenesis found subsequent to day 14 , which was most likely due to the lack of biologically active VEGF at the implantation site. In contrast, the long-term release of rhVEGF achieved with protein incorporation induced a sustained promotion of angiogenesis. rhVEGF coprecipitated onto calcium phosphate ceramics at a concentration of $5 \mu \mathrm{g} / \mathrm{ml}$ induced a significant enhancement of FCD between days 7 and 14 as well as between days 14 and 28 after biomaterial implantation. Hence, the sustained induction of angiogenic processes seemed to depend on the long-term availability of VEGF at the biomaterial implantation site.

During physiological bone healing, the peak expression of VEGF is reached around day 10. Afterwards, VEGF expression decreases gradually (Komatsu and Hadjiargyrou, 2004; Uchida et al., 2003). This pattern of VEGF expression is accompanied by the formation of new blood vessels at the fracture site and a subsequent vessel regression after day 14 (Kleinheinz et al., 2005). VEGF delivery over a period of more than 2 weeks does not reflect the physiological expression pattern of the growth factor and may interfere with the physiological cascade of bone healing. Long-term administration of VEGF may impair ossification and subsequent remodeling of the primary woven bone to lamellar bone. However, it has been shown previously that the promotion of angiogenesis with local delivery of VEGF increased bone density in mandible defects although vessel regression was protracted (Kleinheinz et al., 2005). With respect to bone defect repair in association with bone substitute materials, a prolonged stimulation of angiogenesis may be required to achieve sufficient vascular supply within the 3-dimensional structure of the implant.

The mode of VEGF delivery did not only influence the extent of blood vessel formation but also the morphology and the functionality of the new vasculature. Within the first 14 days rhVEGF adsorbed to BCP ceramics induced the formation of tortuous, immature blood vessels with distinct vascular leakage. In contrast, blood vessels formed upon implantation of ceramic materials coprecipitated with rhVEGF had a more organized and mature appearance. During the entire course of investigation newly formed vessels were well organized and vessel leakage was not enhanced indicating advanced maturation and improved functionality. These findings are in accordance with previous studies investigating VEGFmediated angiogenesis. Unregulated overexpression of VEGF induced hemangioma formation and fatal vascular leakage whereas the prolonged presence of low concentrations of VEGF resulted in the formation of normal blood vessels (Lee et al., 2000; Zisch et al., 2003).

The capacity of VEGF to improve the vascularization of polymeric and calcium phosphate based bone substitute materials has been shown previously (Clarke et al., 2007; Geiger et al., 2005; Geiger et al., 2007; Kaigler et al., 2006; Peng et al., 2002). However, reports on the effect of local VEGF on bone formation are controversial. Some studies described VEGF to enhance the formation of bone; others were not able to demonstrate significant effects of VEGF on bone formation (Clarke et al., 2007; Geiger et al., 2005; Geiger et al., 2007; Huang et al., 2005; Kaigler et al., 2006;
Peng et al., 2005; Samee et al., 2008). In the present study, quantitative histomorphometry revealed that adsorption of rhVEGF at concentrations of $1 \mu \mathrm{g} / \mathrm{ml}$ and $5 \mu \mathrm{g} / \mathrm{ml}$ and coprecipitation of the growth factor at a concentration of $1 \mu \mathrm{g} /$ $\mathrm{ml}$ did not improve material osseointegration nor bone formation. Solely the incorporation of rhVEGF into BCP ceramics at a concentration of $5 \mu \mathrm{g} / \mathrm{ml}$ enhanced bone formation in vivo. These results demonstrate that the local amount as well as the release kinetics of VEGF is of crucial importance for the efficacy of local VEGF delivery to induce bone formation. The mechanisms by which VEGF promotes osseous defect repair include enhanced vascularization leading to an increased supply with osteoprogenitor cells, an increased expression of endothelial cell derived soluble factors regulating osteoblast differentiation, and the direct stimulation of osteoblast migration and differentiation by VEGF (Bouletreau et al., 2002; Clarkin et al., 2008; Gerber et al., 1999; Grellier et al., 2009; Mayr-Wohlfart et al., 2002; Street et al., 2002). These mechanisms were not investigated within the scope of the present study. It is likely that the increase in bone formation found with the sustained release of VEGF was not only mediated via the stimulation of angiogenesis but also by the stimulatory effects of VEGF on osteoblast migration and differentiation. The present results indicate that VEGF primarily promoted biomaterial vascularization while the impact of the growth factor on bone formation was less distinct. Clarkin et al. showed that VEGF did not directly stimulate osteoblast function but that VEGF promoted the activity of osteoblasts via the stimulation of endothelial cells (Clarkin et al., 2008). This indirect action might be a rationale for the requirement of higher concentrations of VEGF to induce bone formation compared to the promotion of angiogenesis.

The sustained release of VEGF appears to be an important factor in the promotion of vascularization and bone formation. At concentrations of $5 \mu \mathrm{g} / \mathrm{ml}$, rhVEGF significantly enhanced the formation of new bone within the pores of the ceramic materials. However, only $23 \%$ of the total pore volume of the materials was filled with newly formed bone although vascularization was well established. These results indicate that the exclusive delivery of a single angiogenic agent may not be sufficient to promote bone formation effectively. A co-delivery of angiogenic and osteogenic factors may be required to promote both biomaterial vascularization and bone formation efficiently without the need for dose escalation of a single agent. BMP-2 may be well suited for a codelivery with VEGF. The growth factor is known for its osteoinductive activity. Furthermore, BMP-2 was shown to promote angiogenesis via the stimulation of VEGF expression by osteoblasts (Deckers et al., 2002). Additionally, VEGF may act synergistically with BMP-2 by indirectly stimulating osteoblast activity through the expression of soluble osteogenic factors by endothelial cells (Clarkin et al., 2008). Recent in vivo studies showed that the combination of VEGF and BMPs synergistically enhanced the effects of either growth factor on bone formation and healing of critical size defects of mice calvariae (Huang et al., 2005; Peng et al., 2005; Peng et 
al., 2002). Future experiments will therefore aim to apply the co-precipitation technique to the co-delivery of VEGF and BMP-2 in order to achieve a long-term delivery of both agents and use their therapeutic potential more efficiently.

In conclusion, the co-precipitation technique improved the retention of rhVEGF on BCP ceramics and achieved a sustained cell-mediated liberation of the growth factor in vitro. In vivo, the modification of the release kinetics increased the efficacy of rhVEGF delivery in the promotion of biomaterial vascularization and bone formation. The data demonstrate that a prolonged bioavailability of VEGF is beneficial for bone regeneration.

\section{Acknowledgements}

The study was supported by grants from the AO Research Foundation, Dübendorf, Switzerland (AO Research Fund No. 05-K82) and the Novartis Foundation for Medicine and Biology, Basel, Switzerland (Grant No. 05B35). Vascular endothelial growth factor (VEGF) was generously supplied by Genentech Inc., South San Francisco, CA, USA.

\section{References}

Baddeley AJ, Gundersen HJ, Cruz-Orive LM (1986) Estimation of surface area from vertical sections. J Microsc 142: 259-276.

Bouletreau PJ, Warren SM, Spector JA, Peled ZM, Gerrets RP, Greenwald JA, Longaker MT (2002) Hypoxia and VEGF up-regulate BMP-2 mRNA and protein expression in microvascular endothelial cells: implications for fracture healing. Plast Reconstr Surg 109: 2384-2397.

Chang BS, Lee CK, Hong KS, Youn HJ, Ryu HS, Chung SS, Park KW (2000) Osteoconduction at porous hydroxyapatite with various pore configurations. Biomaterials 21: 1291-1298.

Clarke SA, Hoskins NL, Jordan GR, Marsh DR (2007) Healing of an ulnar defect using a proprietary TCP bone graft substitute, JAX, in association with autologous osteogenic cells and growth factors. Bone 40: 939-947.

Clarkin CE, Emery RJ, Pitsillides AA, Wheeler-Jones CP (2008) Evaluation of VEGF-mediated signaling in primary human cells reveals a paracrine action for VEGF in osteoblast-mediated crosstalk to endothelial cells. J Cell Physiol 214: 537-544.

Deckers MM, van Bezooijen RL, van der HG, Hoogendam J, van der BC, Papapoulos SE, Lowik CW (2002) Bone morphogenetic proteins stimulate angiogenesis through osteoblast-derived vascular endothelial growth factor A. Endocrinology 143: 1545 1553.

Drake CJ, Little CD (1995) Exogenous vascular endothelial growth factor induces malformed and hyperfused vessels during embryonic neovascularization. Proc Natl Acad Sci U S A 92: 7657-7661.

Ennett AB, Kaigler D, Mooney DJ (2006) Temporally regulated delivery of VEGF in vitro and in vivo. J Biomed Mater Res A 79: 176-184.
Finkemeier CG (2002) Bone-grafting and bone-graft substitutes. J Bone Joint Surg Am 84-A: 454-464.

Gao H, Wang YN, Fan YG, Ma JB (2007) Conjugates of poly(DL-lactide-co-glycolide) on amino cyclodextrins and their nanoparticles as protein delivery system. J Biomed Mater Res A 80: 111-122.

Geiger F, Bertram H, Berger I, Lorenz H, Wall O, Eckhardt C, Simank HG, Richter W (2005) Vascular endothelial growth factor gene-activated matrix (VEGF165-GAM) enhances osteogenesis and angiogenesis in large segmental bone defects. J Bone Miner Res 20: 2028-2035.

Geiger F, Lorenz H, Xu W, Szalay K, Kasten P, Claes L, Augat P, Richter W (2007) VEGF producing bone marrow stromal cells (BMSC) enhance vascularization and resorption of a natural coral bone substitute. Bone 41: 516522.

Gerber HP, Vu TH, Ryan AM, Kowalski J, Werb Z, Ferrara N (1999) VEGF couples hypertrophic cartilage remodeling, ossification and angiogenesis during endochondral bone formation. Nat Med 5: 623-628.

Gerlowski LE, Jain RK (1986) Microvascular permeability of normal and neoplastic tissues. Microvasc Res 31: 288-305.

Grellier M, Ferreira-Tojais N, Bourget C, Bareille R, Guillemot F, Amedee J (2009) Role of vascular endothelial growth factor in the communication between human osteoprogenitors and endothelial cells. J Cell Biochem 106: 390-398.

Guenther HL, Fleisch H, Sorgente N (1986) Endothelial cells in culture synthesize a potent bone cell active mitogen. Endocrinology 119: 193-201.

Gundersen HJ, Jensen EB (1987) The efficiency of systematic sampling in stereology and its prediction. J Microsc 147: 229-263.

Harper J, Klagsbrun M (1999) Cartilage to bone angiogenesis leads the way. Nat Med 5: 617-618.

Hoffmann JN, Vollmar B, Laschke MW, Inthorn D, Fertmann J, Schildberg FW, Menger MD (2004) Microhemodynamic and cellular mechanisms of activated protein $\mathrm{C}$ action during endotoxemia. Crit Care Med 32: 1011-1017.

Horowitz JR, Rivard A, van der Zee R, Hariawala M, Sheriff DD, Esakof DD, Chaudhry GM, Symes JF, Isner JM (1997) Vascular endothelial growth factor/vascular permeability factor produces nitric oxide-dependent hypotension. Evidence for a maintenance role in quiescent adult endothelium. Arterioscler Thromb Vasc Biol 17: 2793-2800.

Huang YC, Kaigler D, Rice KG, Krebsbach PH, Mooney DJ (2005) Combined angiogenic and osteogenic factor delivery enhances bone marrow stromal cell-driven bone regeneration. J Bone Miner Res 20: 848-857.

Kaigler D, Wang Z, Horger K, Mooney DJ, Krebsbach PH (2006) VEGF scaffolds enhance angiogenesis and bone regeneration in irradiated osseous defects. J Bone Miner Res 21: 735-744.

Kanczler JM, Oreffo RO (2008) Osteogenesis and angiogenesis: the potential for engineering bone. Eur Cell Mater 15: 100-114. 
Kempen DH, Lu L, Heijink A, Hefferan TE, Creemers LB, Maran A, Yaszemski MJ, Dhert WJA (2009) Effect of local sequential VEGF and BMP-2 delivery on ectopic and orthotopic bone regeneration. Biomaterials 30: 28162825 .

Kleinheinz J, Stratmann U, Joos U, Wiesmann HP (2005) VEGF-activated angiogenesis during bone regeneration. J Oral Maxillofac Surg 63: 1310-1316.

Klenke FM, Liu Y, Yuan H, Hunziker EB, Siebenrock KA, Hofstetter W (2008) Impact of pore size on the vascularization and osseointegration of ceramic bone substitutes in vivo. J Biomed Mater Res A 85: 777-786.

Komatsu DE, Hadjiargyrou M (2004) Activation of the transcription factor HIF-1 and its target genes, VEGF, HO1, iNOS, during fracture repair. Bone 34: 680-688.

Lee RJ, Springer ML, Blanco-Bose WE, Shaw R, Ursell PC, Blau HM (2000) VEGF gene delivery to myocardium: deleterious effects of unregulated expression. Circulation 102: 898-901.

Leunig M, Yuan F, Menger MD, Boucher Y, Goetz AE, Messmer K, Jain RK (1992) Angiogenesis, microvascular architecture, microhemodynamics, and interstitial fluid pressure during early growth of human adenocarcinoma LS174T in SCID mice. Cancer Res 52: 6553-6560.

Liu Y, Layrolle P, de Bruijn J, van Blitterswijk C, de Groot K (2001) Biomimetic coprecipitation of calcium phosphate and bovine serum albumin on titanium alloy. $\mathrm{J}$ Biomed Mater Res 57: 327-335.

MacNeal WJ (1922) Tetrachrome blood stain: an economical and satisfactory imitation of Leishman's stain. J Am Med Assoc 78: 1122-1123.

Mayr-Wohlfart U, Waltenberger J, Hausser H, Kessler S, Gunther KP, Dehio C, Puhl W, Brenner RE (2002) Vascular endothelial growth factor stimulates chemotactic migration of primary human osteoblasts. Bone 30: 472477.

Murphy WL, Simmons CA, Kaigler D, Mooney DJ (2004) Bone regeneration via a mineral substrate and induced angiogenesis. J Dent Res 83: 204-210.

Nolte D, Zeintl H, Steinbauer M, Pickelmann S, Messmer K (1995) Functional capillary density: an indicator of tissue perfusion? Int J Microcirc Clin Exp 15: 244-249.

Patel ZS, Ueda H, Yamamoto M, Tabata Y, Mikos AG (2008) In vitro and in vivo release of vascular endothelial growth factor from gelatin microparticles and biodegradable composite scaffolds. Pharm Res 25: 23702378.

Peng H, Wright V, Usas A, Gearhart B, Shen HC, Cummins J, Huard J (2002) Synergistic enhancement of bone formation and healing by stem cell-expressed VEGF and bone morphogenetic protein-4. JClinInvest 110: 751759.

Peng H, Usas A, Olshanski A, Ho AM, Gearhart B, Cooper GM, Huard J (2005) VEGF improves, whereas sFlt1 inhibits, BMP2-induced bone formation and bone healing through modulation of angiogenesis. J Bone Miner Res 20: 2017-2027.

Penney DP, Powers JP, Frank M, Willis C, Churukian C (2002) Analysis and testing of biological stains - The Biological Stain Commission Procedures. Biotech Histochem 77: 237-275.

Rucker M, Laschke MW, Junker D, Carvalho C, Schramm A, Mulhaupt R, Gellrich NC, Menger MD (2006) Angiogenic and inflammatory response to biodegradable scaffolds in dorsal skinfold chambers of mice. Biomaterials 27: 5027-5038.

Samee M, Kasugai S, Kondo H, Ohya K, Shimokawa H, Kuroda S (2008) Bone morphogenetic protein-2 (BMP2) and vascular endothelial growth factor (VEGF) transfection to human periosteal cells enhances osteoblast differentiation and bone formation. J Pharmacol Sci 108: 18-31.

Street J, Bao M, deGuzman L, Bunting S, Peale FV, Jr., Ferrara N, Steinmetz H, Hoeffel J, Cleland JL, Daugherty A, van Bruggen N, Redmond HP, Carano RA, Filvaroff EH (2002) Vascular endothelial growth factor stimulates bone repair by promoting angiogenesis and bone turnover. Proc Natl Acad Sci USA 99: 9656-9661.

Uchida S, Sakai A, Kudo H, Otomo H, Watanuki M, Tanaka M, Nagashima M, Nakamura T (2003) Vascular endothelial growth factor is expressed along with its receptors during the healing process of bone and bone marrow after drill-hole injury in rats. Bone 32: 491-501.

Vajanto I, Rissanen TT, Rutanen J, Hiltunen MO, Tuomisto TT, Arve K, Narvanen O, Manninen H, Rasanen H, Hippelainen M, Alhava E, Yla-Herttuala S (2002) Evaluation of angiogenesis and side effects in ischemic rabbit hindlimbs after intramuscular injection of adenoviral vectors encoding VEGF and LacZ. J Gene Med 4: 371380 .

Wernike E, Hofstetter W, Liu Y, Wu G, Sebald HJ, Wismeijer D, Hunziker EB, Siebenrock KA, Klenke FM (2010) Long-term cell-mediated protein release from calcium phosphate ceramics. J Biomed Mater Res A 92: 463-474.

Zisch AH, Lutolf MP, Ehrbar M, Raeber GP, Rizzi SC, Davies N, Schmokel H, Bezuidenhout D, Djonov V, Zilla P, Hubbell JA (2003) Cell-demanded release of VEGF from synthetic, biointeractive cell ingrowth matrices for vascularized tissue growth. FASEB J 17: 2260-2262. 